\title{
COTIDIANO E ORGANIZAÇÃO LABORAL DE TRABALHADORES DE SAÚDE EM PRESÍDIO FEDERAL BRASILEIRO
}

\author{
ROUTINE AND THE LABOR ORGANIZATION OF \\ HEALTHCARE WORKERS IN A BRAZILIAN FEDERAL \\ PRISON
}

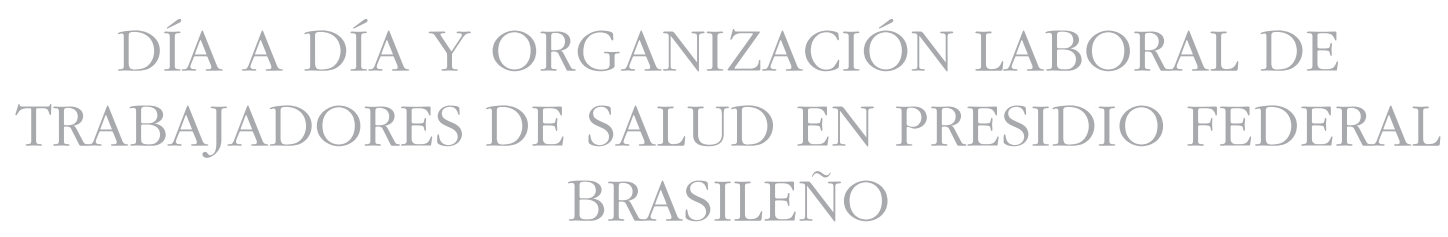

\author{
Lana Jocasta de Souza Brito ${ }^{1}$ \\ Neide Tiemi Murofuse ${ }^{2}$ \\ Laura Adrian Leal ${ }^{3}$ \\ Silvia Helena Henriques Camelo ${ }^{4}$
}

\begin{abstract}
Como citar este artigo: Brito LJS, Murofuse NT, Leal LA, Camelo SHH. Cotidiano e organização laboral de trabalhadores de saúde em presídio federal brasileiro. Rev baiana enferm. 2017;31(3):e21834.

Objetivo: analisar o cotidiano organizacional do trabalho de profissionais da saúde em uma penitenciária federal e a sua influência na saúde desses trabalhadores. Método: estudo exploratório qualitativo com seis trabalhadores da saúde com vínculo efetivo na instituição. Os dados oriundos de entrevistas semiestruturadas foram analisados de acordo com o conteúdo temático. Resultados: os resultados foram agrupados nas categorias temáticas: O cotidiano dos profissionais da saúde para o trabalho na penitenciária federal e A organização de trabalho de saúde na penitenciária federal: divisão de tarefas, baixo controle e sua influência na saúde do trabalhador. A forma de organização de trabalho da penitenciária gera situações ansiogênicas dentro e fora do ambiente de trabalho. O trabalho foi caracterizado como burocrático, sem autonomia e permeado por medo e estado de alerta. Conclusão: os profissionais da saúde que trabalham em uma penitenciária federal percebem as atividades desenvolvidas como tensas, frustrantes e desmotivadoras, podendo acarretar o seu adoecimento pelo trabalho.
\end{abstract}

Descritores: Prisões. Saúde do trabalhador. Condições de trabalho. Pessoal de saúde.

Objective: analyze the work's organizational routine of healthcare professionals in a federal prison, and its influence on the health of these workers. Method: qualitative exploratory study with six healthcare workers holding permanent labor contract with the institution. Data from semi-structured interviews were analyzed according to the thematic content. Results: the results were grouped in the following thematic categories: The routine of healthcare professionals in a federal prison work, and The health work organization in a federal prison: task distribution, low control, and its influence on the workers' bealth. The form of work organization of a prison creates anxiogenic situations inside and outside the workplace. The work was characterized as bureaucratic, with no autonomy, and permeated by fear

\footnotetext{
Enfermeira. Mestranda pela Escola de Enfermagem de Ribeirão Preto. Universidade de São Paulo. São Paulo, SP, Brasil. lana2brito@hotmail.com

Professora. Doutora aposentada da Universidade Estadual do Oeste do Paraná. Cascavel, Paraná, Brasil.

Enfermeira. Mestre. Universidade de São Paulo. São Paulo, SP, Brasil.

Doutora. Professora da Escola de Enfermagem de Ribeirão Preto. Universidade de São Paulo. São Paulo, SP, Brasil.
} 
and alertness. Conclusion: the healthcare professionals working in a federal prison perceive the activities developed as stressful, frustrating, and demotivating, which could trigger a work-related illness process.

Descriptors: Prisons. Worker's health. Working conditions. Health personnel.

Objetivo: analizar la organización laboral cotidiana de profesionales de saluden penitenciaría federal, y su influencia en la salud de los trabajadores. Método: estudio exploratorio, cualitativo, con seis trabajadores de salud con relación de dependencia institucional. Datos recolectados de entrevistas semiestructuradas, analizados según contenido temático. Resultados: los resultados fueron agrupados en las categorías temáticas: Día a día de profesionales de salud trabajando en penitenciaría federal, y Organización del trabajo de salud en penitenciaría federal: división de tareas, bajo control e influencia en la salud del trabajador. La forma de organización del trabajo en la penitenciaría genera situaciones ansiogénicas dentro y fuera del ámbito laboral. El trabajo fue descripto como burocrático, sin autonomía y signado por temor y estado de alerta. Conclusión: los profesionales de salud actuantes en una penitenciaría federal perciben las actividades desarrolladas como tensas, frustrantes y desmotivadoras, pudiendo derivar ello en padecimientos por el trabajo.

Descriptores: Prisiones; Salud Laboral; Condiciones de Trabajo; Personal de Salud.

\section{Introdução}

O trabalho sob a produção capitalista, dada a sua centralidade na vida humana, é gerador de valor, o qual é resultante do trabalho vivo. Para tanto, é preciso submeter as populações aos seus próprios princípios de organização, marcados por aumento da produção e da arrecadação de capital, bem como intensa exploração da força de trabalho e precarização do emprego. Este é um conflito que estrutura as relações sociais e exerce forte influência na saúde dos trabalhadores ${ }^{(1-2)}$.

Apesar de se vivenciar avanços tecnológicos e novas organizações, o trabalho penoso não foi extinto, uma vez que as desigualdades sociais foram acentuadas e trouxeram outro tipo de sofrimento bem mais sutil e complexo: os problemas psíquicos ${ }^{(3)}$.

A organização do trabalho ${ }^{(4)}$ é conceituada como a divisão das tarefas e a divisão dos homens. Esse conceito engloba as responsabilidades do indivíduo no trabalho e a sua execução em si, as relações de poder, as hierarquias, o nível de autonomia do trabalhador, além das possibilidades de emprego da subjetividade, inovação, cooperação e comunicação. Esses recursos e habilidades, quando estão em consonância, são benéficos tanto para a organização de trabalho como para o trabalhador. No entanto, quando esses processos são falhos ou ineficientes, ocupam papel fundamental no entendimento dos processos de adoecimento do trabalhador.

Em busca da compreensão da dinâmica psíquica diante dos conflitos gerados quando ocorre o confronto entre o desejo do sujeito trabalhador e os modelos de gestão do trabalho, surge a psicodinâmica do trabalho, a qual explica que o sofrimento no trabalho é inerente a toda experiência nesse labor ${ }^{(2-3)}$.

A organização de trabalho prisional é comumente retratada de forma depreciativa e estigmatizante, como também considerada arriscada e estressante ${ }^{(5)}$. Dessa forma, considera-se que o trabalhado do profissional da saúde, nesse contexto, requer bastante atenção, por enfrentar preconceitos diversos, dificuldades e limitações laborais decorrentes do próprio ambiente de trabalho fechado. Nesse sentido, este artigo investigou a organização e o contexto de trabalho prisional federal e os trabalhadores de saúde que atuam nesse ambiente.

As Penitenciárias Federais, ao todo cinco unidades existentes no país, diferem dos presídios comuns, que são de custódia estadual, em diversos quesitos: foram construídas seguindo o protótipo estrutural das prisões de segurança máximas americanas supermax; são administradas pela União e destinadas aos condenados de alta periculosidade e lideranças de facções 
criminosas que, durante a sua permanência nos presídios estaduais, colocaram em risco a ordem e a segurança pública ${ }^{(6)}$. Devido a tais características, as atividades de ressocialização e assistência com os presos são bem mais limitadas e as atividades de saúde apresentam aspectos diferenciados das executadas em ambientes extramuros, e até mesmo das que ocorrem em presídios estaduais.

De acordo com estudo ${ }^{(7)}$ realizado com diferentes trabalhadores da área de segurança máxima, os profissionais de saúde desses ambientes foram os mais acometidos com estresse ocupacional. Essa assistência direta aos prisioneiros tem-lhes conferido maior risco de contrair doenças do que os demais funcionários, além dos sofrimentos psicológicos decorrentes das situações de violência e da alta taxa de suicídio de seus assistidos ${ }^{(7)}$. Estudos ainda referem que os arranjos organizacionais de trabalho em ambientes de custódia, que priorizam os problemas ligados à segurança em detrimento das questões relacionadas à saúde, levam os profissionais encarregados do cuidar a vivenciar rotineiramente questionamentos éticos, já que a sua aplicação de trabalho é bastante cerceada ${ }^{(8-9)}$.

A análise da literatura mostra estudos que trazem aspectos relacionados às estruturas organizacionais em presídios estaduais brasileiros. Em relação a isso, há evidências de riscos diários envolvendo agentes penitenciários de instituições estaduais, como condições de trabalho insalubres, pressão e cobranças impostas pelo Estado. Além disso, é observada a falta de suporte psicológico aos trabalhadores ${ }^{(6)}$. No que concerne aos profissionais da saúde, em penitenciárias, um quesito relevante é a sobrecarga de atividades devido à grande defasagem de recursos humanos ${ }^{(8-10)}$.

Nesse sentido, é importante destacar a inexistência de estudos que abordem os profissionais de saúde em presídios federais brasileiros. No geral, a saúde em prisões representa um fenômeno pouco analisado pela literatura nacional. Além do mais, quando ocorrem, são estudos voltados para os agravos de saúde encontrados no cárcere $^{(11)}$ e em realidades estaduais.
As condições salariais oferecidas aos trabalhadores de saúde das penitenciárias federais estão acima da média das que são oferecidas em diversos locais de trabalho na área da saúde, além do fator estabilidade, por ser um emprego público. Apesar disso, a prática profissional de uma das autoras desta investigação revela que, no âmbito de um presídio federal, os profissionais permanecem visivelmente estressados e desmotivados. Nessa perspectiva é que surgiu o interesse de entender o que acontece no cotidiano desse trabalho e como ele se organiza e também como esses descontentamentos podem advir dessa estruturação organizacional e desse cotidiano de trabalho.

Dessa maneira, cotidiano é entendido como aquilo que se apresenta ou é compartilhado no dia a dia. São as práticas corriqueiras das pessoas que, mesmo denotadas como rotina ou conjunto de atividades comuns, representam um campo muito rico e que é influenciado por regras e convenções sociais ${ }^{(12)}$. Nesse quesito, o cotidiano emerge como um espaço de contínua tensão, atravessado por instituições disciplinares e por diversificadas práticas culturais ${ }^{(13)}$.

Levando-se em conta essa realidade, surgiram as seguintes indagações: Como se dá a rotina diária do trabalhador de saúde que atua em uma penitenciária? Como ocorre a divisão de tarefas? Existe autonomia? Como o trabalho pode influenciar na sua saúde?

Esta pesquisa com enfoque em saúde do trabalhador tem a intenção de colaborar com elementos para a compreensão da relação entre o mundo do trabalho no interior dos presídios brasileiros e as consequências para a saúde dos trabalhadores que lá atuam, principalmente no que concerne aos trabalhadores da área da saúde.

Assim, este estudo teve o objetivo de analisar o cotidiano organizacional do trabalho de profissionais da saúde em uma penitenciária federal e a sua influência na saúde desses trabalhadores.

\section{Método}

Trata-se de um estudo exploratório de abordagem qualitativa. Este tipo de estudo preocupa-se com um nível de realidade que não pode 
ser quantificado, envolve um universo de significados, motivos, aspirações, crenças, valores e atitudes, além de permitir o aprofundamento na compreensão da realidade humana vivida socialmente ${ }^{(14)}$.

Este artigo resulta de um recorte do trabalho de conclusão de curso da Especialização em Saúde Pública pela Universidade Estadual do Oeste do Paraná (Unioeste), Brasil. As entrevistas foram conduzidas por uma das autoras que, além de pesquisadora, compunha o quadro de trabalhadores de saúde da penitenciária estudada, no caso uma penitenciária de segurança máxima federal localizada no estado do Paraná. O entrosamento e a abertura da pesquisadora com o universo pesquisado facilitaram a abordagem e o andamento da pesquisa.

O Sistema Penitenciário Federal (SPF) estudado foi implantado no ano de 2006, porém somente em 2009 foram instituídos os cargos de especialista em assistência penitenciária e de técnico de apoio à assistência penitenciária. O cargo de especialista é de nível superior, das áreas de saúde e educacional, tais como: médicos, farmacêuticos, enfermeiros, psicólogos, dentistas, terapeutas ocupacionais, assistentes sociais e pedagogos. No cargo técnico, composto por técnicos de enfermagem e auxiliares de consultório dentário, é exigida escolaridade média com formação técnica ${ }^{(15)}$.

Os profissionais de saúde, isto é, especialistas e técnicos, foram convidados pessoalmente para participarem da pesquisa. Assim sendo, foram especificados todos os itens do Termo de Consentimento Livre e Esclarecido (TCLE), os objetivos da pesquisa, os procedimentos de coleta de dados e a garantia do anonimato. Aqueles que aceitaram participar escolheram a data e o local de encontro e todos preferiram realizá-lo nos seus respectivos domicílios, por considerarem um ambiente reservado.

Adotou-se como critério de inclusão dos participantes da pesquisa a atuação como profissional de saúde com experiência de no mínimo seis meses na atividade e de vínculo efetivo.

Portanto, no universo de 11 profissionais de saúde desse local, participaram deste estudo 6 trabalhadores, sendo 4 do cargo de especialista em assistência penitenciária (1 enfermeiro, 1 psicólogo, 1 farmacêutico, 1 odontólogo) e 2 com cargo de técnico de apoio à assistência penitenciária (1 técnico de enfermagem e 1 técnico em saúde bucal). Houve duas recusas em participar da pesquisa, uma referiu não se sentir à vontade para se expor na pesquisa, mesmo com a garantia de anonimato, e a outra, porque, durante a execução das entrevistas, pediu exoneração do presídio para assumir emprego em outro concurso no seu estado de origem. Também foram excluídos do grupo, a pesquisadora e um profissional que respondeu a uma entrevista preliminar para teste do instrumento de coleta de dados. A aplicação do teste possibilitou a análise do seu resultado, ao tempo em que foram feitas as devidas adequações e revisões do instrumento.

A entrevista semiestruturada, que teve duração aproximada de 30 minutos e foi gravada e transcrita na íntegra, foi utilizada para a coleta de dados. O número de entrevistados foi determinado pelo processo de repetição, cessando quando os dados coletados tornaram-se repetitivos e permitiram a compreensão do fenômeno estudado. Os entrevistados eram, na maioria, do sexo feminino, no caso quatro; todos com idade variando entre 28 e 44 anos, com estado civil apresentando proporcionalidade entre solteiros e casados. Os participantes foram identificados pela letra "D" seguida de uma numeração em algarismo arábico sequencial, garantindo-se, assim, o anonimato das falas.

O corpus da análise foi composto pelo material transcrito das gravações. Para tanto, optou-se pela utilização da modalidade da análise temática de conteúdo, que se desenvolveu em três etapas. A primeira, consistiu na tomada do contato com o material obtido, mediante a realização de leituras e releituras. Num segundo momento, realizou-se a codificação das informações, que consistiu na identificação de frases e temas. Na terceira etapa, procedeu-se ao agrupamento do material codificado de acordo com a similaridade temática e os objetivos do estudo $^{(14)}$. Cabe destacar que, para a identificação das unidades temáticas relacionadas à 
organização e rotina de trabalho em saúde da penitenciária, foram levados em conta os depoimentos dos entrevistados. Para efeito deste estudo, entende-se que a organização de trabalho não é somente a divisão do trabalho, mas, principalmente, as divisões das tarefas e dos homens ${ }^{(4)}$.

O estudo foi aprovado pelo Comitê de Ética em Pesquisa (CEP) da Universidade do Oeste do Paraná (Unioeste) sob Parecer n. 167/2011. A pesquisa seguiu os princípios éticos norteadores dispostos na Resolução n. 196/96, que regulamenta as pesquisas com seres humanos.

\section{Resultados e Discussão}

A preponderância feminina obtida no presente estudo está em consonância com o fenômeno de maior inserção da mulher em trabalhos fora do lar, mesmo em áreas e locais de trabalho hegemonicamente masculinos, como polícias, segurança, presídios e engenharia. No entanto, apesar do discurso oficial de neutralidade de gênero, emergem informalmente brincadeiras e comentários que excluem as mulheres e demarcam a diferença de gênero ${ }^{(16)}$.

Em ambientes masculinizados, espera-se o comportamento socialmente exercido pelo homem, que é a força e a repreensão, assim como a necessidade constante de afirmação da virilidade. Logo, atividades de caráter assistencial e com predomínio de trabalhadores do sexo feminino, como as do setor da saúde, são pouco valorizadas $^{(17)}$.

Estudo realizado com agentes penitenciárias femininas revelou que as mulheres relatam mais estresse associado a trabalho em penitenciárias do que os homens, provavelmente por razões culturais, de serem mais vulneráveis a tensões no trabalho, com menos recursos físicos de reagir à violência e com mais dificuldade de se impor como autoridade, assim como a necessidade de firmar-se como profissionais capazes nesses ambientes ${ }^{(18)}$.

Em reação à atividade desenvolvida, a equipe de saúde entrevistada relatou que o presídio federal não foi o primeiro emprego. Dois $(33,33 \%)$ entrevistados tiveram a experiência anterior em emprego público municipal, um (16,66\%) com emprego público estadual, um $(16,66 \%)$ com emprego público federal, um $(16,66 \%)$ na iniciativa privada e um $(16,66 \%)$ em cargo comissionado. Para assumir tais cargos, os discursos revelaram alguns aspectos inerentes ao próprio trabalho, conforme descrito a seguir.

Estabilidade, salário fixo, algumas garantias que como autônoma eu não tinha. (D1).

O fato de ser servidor público federal, mas principalmente o salário, porque, com o curso técnico que eu tenbo aqui, realmente eu ganho bem. É que sou técnico e, para meu nível, aqui é que se ganha melhor. (D6).

Na verdade, lá eu caí de pára-quedas [...] não é que eu tenha escolbido, mas foi uma opção que surgiu, ai eu fui lá e passei e tô aqui. (D6).

Tais motivações corroboram a constatação de que a escolha profissional daqueles que realizavam a vigilância prisional processa-se em razão da necessidade de obtenção de sustento e não considera o desejo do sujeito. Algumas pesquisas com agentes penitenciários revelam que as motivações para trabalhar em uma penitenciária foram: relativa sensação de estabilidade do emprego; por ser serviço público; e o salário que, na conjuntura nacional, em que há elevados níveis de desemprego no país, se comparado a outros cargos públicos, possui gratificações que agregam ao valor final ${ }^{(18-20)}$.

A análise dos discursos possibilitou a elaboração de duas categorias: "Cotidiano dos profissionais da saúde para o trabalho na penitenciária federal" e "Organização de trabalho de saúde na penitenciária federal: divisão de tarefas, baixo controle e sua influência na saúde do trabalhador". Permitiram, ainda, reflexões sobre a rotina de trabalho dos profissionais de saúde de uma penitenciária.

\section{Cotidiano dos profissionais da saúde para o trabalbo na penitenciária federal}

O presídio estudado situa-se em um município no interior do estado do Paraná, Brasil, com cerca de 10 mil moradores. O projeto do SPF surge com o objetivo de isolar os principais líderes de facções criminosas e presos de alta periculosidade, aliado a uma proposta de custódia 
mais humanizada. Para garantir o cumprimento da pena estipulada ao preso, privado da liberdade de ir e vir, mas com direitos como a saúde, o SPF possui uma equipe de saúde multiprofissional, para atender as necessidades de saúde dessa população.

Para chegar ao local de trabalho, os trabalhadores percorrem cerca de $90 \mathrm{~km}$ diariamente, por residir em município distinto, situado a $45 \mathrm{~km}$ de distância, e que oferece melhor qualidade de vida e infraestrutura, como hospitais, creches, lazer e cultura. Eles se organizam em caronas, revezando os carros, e enfrentam uma rodovia bastante movimentada com tráfego de carretas, carros e caminhões. Este aspecto foi avaliado pelos entrevistados como sendo perigoso, devido ao alto índice de acidentes registrado no trajeto casa-trabalho-casa. Logo, isso já representa um fator ansiogênico, conforme o depoimento a seguir:

A rodovia é muito perigosa, todo dia pegar estrada. Já vimos muitos acidentes indo para o trabalbo. (D3).

O presídio estudado impõe bastante rigor na segurança, visando minimizar falhas no controle que possam ocasionar corrupção e prática de atos ilícitos. Em nome da segurança, o trabalhador da saúde, como os demais servidores, ao chegar à penitenciária, submete-se a processos e procedimentos, como pórticos de detectores de metais e máquinas de Raios-X. Essas são reguladas para serem mais sensíveis aos metais do que as que estão disponíveis em aeroportos. No SPF, o funcionário que transitar com metais, celulares ou qualquer material que possa, por ventura, ser utilizado por algum preso, poderá sofrer sanções disciplinares e até ser demitido.

A cada portão tem uma pessoa [agente] e os aparelbos de detectores de metais [...] eu me sentia meio desprestigiada, pensando que aquilo era porque estavam desconfiando da gente. Hoje eu sei que é muito importante passar por isso, pois, se amanhã ou depois der algum problema, eu fui revistada, não desconfiarão de mim. (D1).

A intensa vigília realizada pelos detectores de metais e câmeras de vigilância é uma forma de exercer o poder disciplinar, livre de punições físicas, dentro das penitenciárias. Essas tecnologias induzem no detento um estado consciente e permanente de visibilidade, o que os condiciona a mostrar bom comportamento, já que sabem que estão sendo vigiados ${ }^{(13)}$.

No entanto, esse monitoramento ramifica-se nas microlocalidades, sendo transmitido entre os diversos indivíduos. Logo, pode incidir nos trabalhadores que ali laboram, como é observado no discurso acima, no qual o trabalhador sente a necessidade de provar sua idoneidade. Isso ocasiona uma atmosfera de cobrança intensa no sujeito $^{(13)}$.

Indubitavelmente, a vigilância evidencia o poder da visibilidade, e esse representa uma das principais formas de relação de poder no cotidiano de uma sociedade disciplinar, modulando atitudes e comportamentos ${ }^{(13)}$. Os trabalhadores, por conseguinte, passam pela mesma ritualização de valor simbólico que os presos também passam, já que devem respeitar as mesmas regras e também são isolados do ambiente externo, mesmo que temporariamente ${ }^{(21)}$.

\section{Organização de trabalbo de saúde na penitenciária federal: divisão de tarefas, baixo controle e sua influência na saúde do trabalbador}

O ambiente de trabalho do setor de saúde no SPF possui: sala para atendimento médico, ambulatório equipado para fazer pequenas cirurgias, consultório odontológico, enfermaria com três leitos (para pequenas intervenções, como soroterapia), sala para atendimento psicológico, farmácia, sala de esterilização e três celas ao fundo, para manter até três presos em observação da saúde. A estrutura física e de equipamentos está em consonância com o que é recomendado pela politica carcerária ${ }^{(22)}$.

Quando um preso é admitido na penitenciária, ele passa pelo setor da saúde, é atendido pela equipe multiprofissional, é feita uma triagem, são submetidos a exames sanguíneos para controle e avaliação da condição de saúde e detecção de doenças preexistente ou infecto-contagiosa, vacinação, controles (hipertensão e diabetes) entre outros. Os atendimentos subsequentes, exceto os de urgência e emergência, 
são solicitados pelo preso, mediante um instrumento de comunicação chamado de "requerimento". Qualquer conduta ou locomoção dentro do presídio é intermediada por um agente da segurança, incluída a execução dos serviços de saúde. Para a execução do serviço solicitado, os trabalhadores de saúde ficam na dependência do setor de segurança da penitenciária, como está ilustrado nos depoimentos a seguir:

Chego e planejo os atendimentos, solicito, verifico a possibilidade de ter agentes penitenciários para conduzir os internos até o serviço de saúde, se tem como levar o interno para o consultório eu faço o atendimento. (D1).

Eu chego e preparo uma lista de atendimento. Antes de atender, eu verifico com a chefia de segurança se há disponibilidade de agentes para eu realizar o atendimento. (D3).

Assim, os trabalhadores da saúde solicitam aos chefes das vivências (galerias) a condução do preso até ao setor de saúde. Durante todo o atendimento ele fica algemado e é acompanhado por no mínimo dois agentes de segurança.

São inúmeras as dificuldades para o desenvolvimento de ações de saúde nas prisões, já que essas representam um espaço que prioriza práticas punitivas ${ }^{(11)}$. Uma notória medida de segurança do SPF é evitar saídas desnecessárias do preso para o meio externo, a fim de diminuir as chances de fuga ou a exposição dos agentes, profissionais de saúde (que, muitas vezes, acompanham a escolta desse preso a um hospital, por exemplo) e população. Logo, se a patologia do interno exigir tratamento mais específico e fora do ambiente prisional, os profissionais da saúde devem motivar e respaldar o encaminhamento.

O quadro de pessoal da instituição não conta com médicos efetivos. O atendimento é realizado por um médico contratado para atender no interior do presídio, mas nem sempre é possível a contratação. A ausência desse profissional dificulta a dinâmica do setor da saúde e afeta diretamente o enfermeiro, pela exposição maior aos questionamentos e exigências dos presos, e resulta em sobrecarga de pedidos e demandas. O enfermeiro, além de ser o elo para o atendimento médico, é o profissional que mais interage com os internos, por entregar a medicação três vezes por semana, de cela em cela, realizar acompanhamento de pressão arterial, glicemia, coleta de sangue e outros procedimentos.

Sabe-se que a população carcerária requer mais assistência médica do que a população não fechada em cárcere, pois o próprio ambiente prisional favorece a maior incidência de problemas de saúde. O estresse decorrente do encarceramento, das condições insalubres, o número significativo de casos de DST/AIDS, tuberculose, pneumonias, dermatoses, hepatites, bem como transtornos mentais e o maior risco de suicídio são alguns acometimentos ${ }^{(23-24)}$.

Conforme a política carcerária, a equipe técnica de saúde mínima das unidades prisionais com mais de 100 presos, que é o caso da penitenciária estudada, deve ser composta por médico, enfermeiro, dentista, psicólogo, assistente social, auxiliar de enfermagem e atendente de consultório dentário, com jornada de 20 horas semanais. Para os estabelecimentos prisionais que já contarem com quadro de saúde, a equipe será complementada ${ }^{(22)}$, ainda que esse local passe por longos períodos sem assistência constante do médico clínico e do médico psiquiatra. Logo, a prescrição de psicotrópicos, o acompanhamento e a realização de condutas no manejo aos acometidos pela síndrome de abstinência a álcool ou drogas fica impedida, assim como não está em conformidade com o que preconiza a política de saúde para essa população.

O farmacêutico tem respaldo técnico para analisar a prescrição médica, o modo e a via de administração adequada, garantindo o uso correto e seguro dos medicamentos. Logo, ele previne erros de medicação e aumenta a qualidade do cuidado ao paciente e segurança em relação à terapia medicamentosa ${ }^{(25)}$.

No contexto da penitenciária, o profissional farmacêutico controla o estoque de medicação, realiza as licitações e os pedidos de medicamentos, auxilia o médico sobre os medicamentos padronizados na penitenciária e os que supostamente não são seguros naquele ambiente. Entre outras funções, ele prepara a caixa organizadora de medicamento que é entregue ao preso pelo profissional de enfermagem. Essa 
caixa é identificada com o nome do interno, da medicação e o respectivo horário ${ }^{(25)}$.

O profissional de enfermagem entrega a caixa de medicamento ao preso, na vivência, acompanhado pelo agente do setor de segurança. A atividade exige constante atenção no sentido de evitar algum veículo de medicamento que possa ser utilizado como arma e causar algum dano à integridade do próprio preso, dos demais custodiados ou dos trabalhadores. Neste sentido, antes de deixar qualquer material ou medicação com o preso, é necessária a avaliação e autorização do setor da segurança.

Outro ponto importante é a deficiência quantitativa de profissionais, que resulta no acúmulo de função daqueles que estão presentes, como se vê no discurso seguinte.

Deveria ter mais profissionais. Acho muito puxado ter um psicólogo só, uma dentista só. Poderia ser maior o número de profissionais. (D3).

À quantidade pequena de trabalhadores some-se o quesito carga horária. De acordo com a política que regula a saúde em ambientes carcerários, a jornada de trabalho recomendada é de 20 horas semanais ${ }^{(22)}$. Ainda que a lei que regula os cargos no SPF preconize 40 (quarenta) horas semanais em regime de expediente ( 8 horas diárias) ou em regime de plantão (plantões de 24 horas por 72 horas de descanso) ${ }^{(26)}$, na prática, os servidores especialistas e técnicos, na sua maioria, atuam em regime de expediente e em contato direto com o preso diariamente. Somente a equipe de enfermagem trabalha em regime de plantão de 24 por 72 horas.

É muito estressante ir para aquele lugar todo dia. É uma carga pesada. Lugar negativo. 40 horas é muita coisa. (D5).

Conforme os entrevistados, o ritmo de trabalho estava diretamente relacionado à disponibilidade de agentes de segurança na condução dos internos para o atendimento no setor de saúde ou para acompanhar o profissional até a cela:

Depende, há dias que é muito corrido e há dias que é bem tranquilo. (D3).
A falta de sistematização e de rotina das tarefas faz o trabalho adquirir caráter de improvisação, o que implica tanto em dificuldades na sua execução quanto na exposição a críticas e/ou represálias por parte do preso, das pessoas de outros setores ou mesmo do próprio profissional $^{(19)}$.

O intervalo do almoço, para a equipe de saúde entrevistada, foi considerado um momento de relaxamento. Visto como uma oportunidade para desfrutar da interação com o colega num clima diferente da sua realidade cotidiana de trabalho, marcada por um tempo linear e rotineiro de uma organização em que se evitam contatos densos, assuntos pessoais na frente dos presos e exige resguardo e alerta. Assim, quando se criam oportunidades de pequenas fugas de uma rotina massacrante, despreza-se o perigo, camuflando os medos e os riscos momentaneamente, o que representa um mecanismo de defesa necessário para a produtividade do trabalhador em ambientes hostis ${ }^{(27)}$.

A gente faz questão de comer fora da penitenciária. Você se desliga daquele ambiente. (D2).

Outro fator constatado foi o modo de organização do trabalho. Os entrevistados estavam formalmente subordinados diretamente ao diretor e ao chefe de saúde da penitenciária e informalmente à divisão de segurança, já que, para desenvolver qualquer procedimento com o preso, havia necessidade da presença de no mínimo dois servidores da penitenciária, sendo pelo menos um agente de segurança. A fala a seguir é ilustrativa:

Eu acho que não tem [autonomia], depende muito da segurança. No contato com os internos, a gente precisa deles, não tem contato direto com eles, sempre tem que ter um agente para nos acompanhar. (D2).

A subordinação a outros níveis hierárquicos implica na necessidade de reportar-se a diferentes pessoas para a execução do trabalho. Entretanto, nem sempre o cargo de chefia é ocupado por pessoas da mesma área ou formação dos subordinados. Em um ambiente em que a segurança é primordial, geralmente o cargo de diretor é ocupado por agente de segurança. 
Este fato pode dificultar a sensibilização para as questões de saúde.

Alguns estudos relatam que o baixo controle sobre o trabalho dificulta o alcance das metas assistenciais formalmente prescritas. No âmbito prisional, os atores envolvidos com o compromisso de garantir acesso à saúde enfrentam a falta de autonomia e a dependência do funcionamento da segurança, fazendo com que a sua prática torne-se, muitas vezes, reduzida a papéis complementares, impossibilitando decisões, inviabilizando a liberdade de ação e impedindo o controle das tarefas pelo trabalhador, podendo, assim, levar o trabalhador ao processo de adoecimento ${ }^{(28-29)}$.

Outra relação a se considerar é aquela estabelecida entre os trabalhadores da saúde e a população assistida no presídio. Enquanto em outros locais, o trabalhador de saúde empenha-se em estabelecer com o usuário uma relação de empatia, em um presídio federal, ele busca manter o distanciamento e a imparcialidade, focando a atenção na patologia e evitando qualquer vínculo, seja de animosidade, seja de amizade. Isso se deve, conforme os entrevistados, ao fato de essa relação ser permeada por dificuldades e exigências, como ilustra a fala a seguir:

O apenado é um cliente bastante difícil de lidar. Ele questiona muito, ele é cheio dos direitos, ele grita, tudo que se faz nunca está bom para ele, quer tomar a medicação que ele quer, quer exigir muito. (D5).

Em um presídio, pequenas práticas cotidianas podem gerar indisposição entre sentenciados e trabalhadores, tais como: a exigência de determinado medicamento ou de algum atendimento pela equipe interdisciplinar. Além disso, o ambiente prisional é marcado por um cotidiano de opressão, já que é destinado ao controle social das classes populares. Nesse ambiente social degradado, o medo e a violência fazem parte da rotina. Funcionários entrevistados em um presídio estadual referiam-se aos presos como desprovidos de disciplina e de respeito, dotados de muitos direitos devido às leis brandas, à impunidade e à falta de firmeza da justiça ${ }^{(19)}$.

Desse modo, ficaram evidentes o receio ou medo do trabalhador em relação à clientela assistida, conforme relatado a seguir:
É muito delicada essa situação. A gente tem que sempre estar lembrando quem eles são, do que são capazes de fazer. (D1).

O medo de atentados à sua integridade física, sentimentos de apreensão, temor pela exposição de sua família e o sentimento de estar em perigo são algumas vivências ansiogênicas causadoras de sofrimento e de possível adoecimento às quais os trabalhadores do cárcere estão sujeitos. A exposição a riscos psicossociais decorrentes da tensão e da violência coloca-os sempre em alerta, seja nas atividades internas aos muros de uma cadeia, seja nas atividades extramuros desenvolvidas de maneira individual, familiar ou social $^{(20)}$. O relato a seguir é ilustrativo:

Muitos não ficarão presos pelo resto da vida. Eles sairão e, se sentirem que não gostou de alguém, eles não têm nada a perder, né? (D4).

Quanto à relação com os colegas de trabalho agentes e pares da saúde, os entrevistados consideraram as relações amistosas e saudáveis. Nesse sentido, um contexto laboral que adota relacionamentos mais respeitosos e cordiais entre as equipes diminui a violência que opera nas instituições de trabalho em suas múltiplas modalidades (psicológica, institucional, física e sexual), assim como condutas discriminatórias, colaborando para uma subjetividade saudável entre os profissionais e os demais envolvidos ${ }^{(30)}$. Isto fica evidenciado no fragmento a seguir:

Meus amigos são do trabalbo. A maioria das pessoas do trabalbo também são de fora, não tem família aqui. Então, a gente se une e forma uma família. (D1).

Estudos identificaram que medo, tensão, exposição constante ao perigo e ambiente de repressão podem elevar os índices de doenças físicas e transtornos mentais, elevando o número de afastamentos e de absenteísmo no trabalho. As principais doenças encontradas em trabalhadores da área penal por esses estudos foram: gastrites, cefaleia, depressão, sensação de "estar acabado”, insônia, estresse e fadiga crônica ${ }^{(18-20)}$.

A conduta do trabalhador da saúde dentro do ambiente carcerário deve ser de alerta também em relação aos seus procedimentos técnicos, já que isso implica em readaptação de suas práticas profissionais para torná-las mais apropriadas 
para o ambiente. Qualquer conduta do trabalhador, em relação aos cuidados de saúde do preso, só é realizada após a segurança julgar os possíveis riscos e avaliar o procedimento como aplicável e seguro. Esta prática, entretanto, destoa daquela aprendida durante a formação profissional. Assim, os profissionais de saúde deparam-se com o dilema do distanciamento entre a formação acadêmica e a experiência profissional.

Um fator comportamental que acomete os trabalhadores é um processo chamado de "prisionização", entendida como a assimilação da cultura prisional, que se caracteriza pelo linguajar local, modo de pensar, costumes e hábitos que geralmente são dos internos. Isso resulta em conflitos de valores, visto que os trabalhadores carregam valores da sociedade livre que irá chocar-se com os constituídos dentro do sistema. Essa ambivalência exige do trabalhador necessidades adaptativas, a fim de garantir sua sobrevivência no sistema, mas isso gera tensão no indivíduo motivada pela repressão de sentimentos e controle da agressividade ${ }^{(28)}$. Portanto, todos os que adentram um sistema penitenciário, preso ou trabalhador, são sujeitados, de alguma forma, pela organização, funcionamento e situações de risco vivenciadas nesse local ${ }^{(27)}$. Com a população estudada não aconteceu diferente.

A análise do cotidiano e da organização do trabalho do presídio federal de segurança máxima permitiu constatar-se a existência de peculiaridades e situações organizacionais que repercutem na saúde do trabalhador. O sistema de vigilância, por exemplo, além de monitorar o preso, permitia também o monitoramento das ações de saúde, possibilitando a avaliação e o questionamento das condutas profissionais adotadas, tanto por pessoas internas à penitenciária quanto por pessoas alheias ao presídio, como, por exemplo, os advogados dos presos. Com isso, o modelo panóptico (visibilidade) referido por Foucault ${ }^{(13)}$ também se reproduzia com os trabalhadores.

O trabalho da equipe de saúde é executado com baixo nível de controle em decorrência da subordinação hierárquica e da dependência da divisão de segurança, até mesmo em aspectos privativos da profissão; baixo poder decisório e de valorização dos trabalhadores no processo de gestão do trabalho; burocracia; ausência de programas computacionais que implicava em atividades de cunho artesanal; acúmulo de funções; ausência de profissionais; rotina de trabalho improvisada e ritmo de trabalho inconstante e dependente; carga horária extensa; além do clima de constante alerta, tensão e medo.

A naturalização e banalização da violência nesses locais adoecem os profissionais que trabalham nas prisões e não recuperam nenhum indivíduo preso que vivencia esses fenômenos cotidianamente. Nesse sentido, esses fenômenos refletem-se na sociedade, pois o indivíduo preso que vive essas situações adversas possivelmente levará essa hostilidade para fora dos limites das prisões, quando egresso. Desse modo, o adoecimento que acomete o trabalhador é reflexo de um modelo confinador que pouco tem considerado essa problemática.

Sem dúvida, há muitas questões por explorar no avanço do conhecimento das repercussões do trabalho de saúde em uma penitenciária federal. A elevada carência de estudos sobre os profissionais de saúde que atuam em organizações totais, como as prisões, fica evidente, quando o assunto saúde carcerária é debatido. Quase sempre o foco são os agravos que acometem a população encarcerada e pouco se explora a saúde do cuidador.

Espera-se que esta pesquisa possa contribuir para ampliar o conhecimento dos problemas existentes no trabalho de saúde dentro de uma penitenciária, como também para desmistificá-lo, já que é bastante desconhecido pelos demais profissionais de saúde e pela sociedade. Por meio da apropriação do saber e conscientização dos problemas, gerentes, políticos, profissionais de saúde e a sociedade civil podem engajar-se na solução de desafios históricos tanto nas condições de trabalho prisional quanto no cuidado do preso.

Este estudo possui como limitação o fato de a investigação acontecer em uma única penitenciária, o que reduz o número de participantes. 
Logo, recomenda-se a realização de outras pesquisas, envolvendo outras penitenciárias, com vistas a possibilitar comparações e possíveis generalizações que forneçam subsídios para o melhor embasamento e ampliação da análise.

\section{Conclusão}

O cotidiano organizacional do trabalho de profissionais da saúde em uma penitenciária federal contribui para a baixa satisfação, o descontentamento e a desmotivação no trabalho. Existe o receio em relação à população assistida e de serem interpelados tanto dentro quanto fora dos limites da cadeia. O embate diário com diversas formas de manifestação de violência resulta em desgastes emocionais, sendo minimamente atenuado pela existência do bom relacionamento entre os colegas de trabalho.

A violência vivida no trabalho pelos participantes não pode deixar de ser considerada pela gestão. A adoção de medidas no sentido de promover a saúde e prevenir os agravos de saúde do trabalhador, diminuir situações de violência e a exposição a elas, por meio da redução da jornada de trabalho, atenuaria a carga tensional nesse ambiente de trabalho.

Pôde-se concluir que os profissionais da saúde que trabalham em uma penitenciária federal percebem as atividades desenvolvidas como tensas, frustrantes e desmotivadoras, podendo acarretar o seu adoecimento pelo trabalho.

\section{Colaborações:}

1. concepção, projeto, análise e interpretação dos dados: Lana Jocasta de Souza Brito e Neide Tiemi Murofuse;

2. redação do artigo e revisão crítica relevante do conteúdo intelectual: Laura Adrian Leal;

3. aprovação final da versão a ser publicada: Silvia Helena Henriques Camelo.

\section{Referências}

1. Braz VAGA. O trabalhador entre a saúde e a (in) segurança do trabalho. EM PAUTA [internet]. 2013 [cited 2016 Sept 20];11(32):273-95. Available from: http://www.e-publicacoes.uerj.br/index.php/ revistaempauta/article/view/10166

2. Wanderlli LV. Da psicodinâmica do trabalho ao direito fundamental ao conteúdo do próprio trabalho e ao meio ambiente organizacional saudável. Rev eletrôn curso Direito UFSM [internet]. 2015 [cited 2016 Sept 16];10(1):193-217. Available from: https://periodicos.ufsm.br/revistadireito/ article/view/19239

3. Augusto MN, Freitas LG, Mendes AM. Vivências de prazer e sofrimento no trabalho de profissionais de uma fundação pública de pesquisa. Psicol Rev [internet]. 2014 [cited 2016 Sept 12];20(1):3455. Available from: http://periodicos.pucminas. br/index.php/psicologiaemrevista/article/ view/P.1678-9523.2014v20n1p34

4. Dejours CA. Loucura do trabalho: estudo de psicopatologia do trabalho. São Paulo: Cortez; 1992.

5. Barcinski M, Altenbernd B, Campani C. Entre cuidar e vigiar: ambiguidades e contradições no discurso de uma agente penitenciária. Ciênc saúde coletiva [internet]. 2014 [cited 2016 Sept 20];19(7):2245-54. Available from: http://www.scielo.br/scielo.php?script=sci_ arttext\&pid=S1413-81232014000702245

6. Reishoffer JC, Bicalho PPG. O regime disciplinar diferenciado e o sistema penitenciário federal: a "reinvenção da prisão" através de políticas penitenciárias de exceção. Rev Polis Psique [internet]. 2013 [cited 2017 July 20];3(2):162-84. Available from: http://seer.ufrgs.br/index.php/ PolisePsique/article/viewFile/43094/28734

7. Akbari J, Akbari R, Farasati F, Mahaki B. Job stress among Iranian prison employees. Int J Occup Environ Med [internet]. 2014 [cited 2017 July 20];5(4):208-15. Available from: https://www.ncbi. nlm.nih.gov/pmc/articles/PMC5433637/

8. Cartaxo RO, Costa GMC, Celino SDM, Cavalcanti AL. Panorama da estrutura presidiária brasileira. Rev Bras Promoc Saude [internet]. 2013 [cited 2016 Sept 12];26(2):266-73. Available from: http://ojs. unifor.br/index.php/RBPS/article/view/2916

9. Valente GSC, Santos FS. A complexidade do trabalho de enfermagem no hospital custódia e tratamento psiquiátrico. Rev pesq cuid fundam (online). 2014 [cited 2016 Sept 20];6(1):109-17. Available from: http://www.seer.unirio.br/index. $\mathrm{php} /$ cuidadofundamental/article/view/2871 
10. Paiuca JM. A experiência do trabalho do serviço social junto aos carcereiros da cadeia feminina de Franca/SP [dissertação]. Franca (SP): Universidade Estadual Paulista; 2014.

11. Jesus LO, Scarparo HBK, Lermen HS. Desafios profissionais no campo da saúde no sistema prisional: dilemas na interface entre a saúde e a segurança. Aletheia [internet]. 2013 [cited 2016 Sept 20];(41):39-52. Available from: http:// pepsic.bvsalud.org/scielo.php?pid=S1413$03942013000200004 \&$ script $=$ sci_abstract

12. Certeau M, Giard L, Mayol P. A invenção do cotidiano. 2. Morar, cozinhar. Petrópolis: Vozes; 2009.

13. Foucault M. Vigiar e punir: história da violência nas prisões. Tradução de Raquel Ramalhete. 41a ed. Petrópolis: Vozes; 2013.

14. Minayo MCS. O desafio do conhecimento: pesquisa qualitativa em saúde. 12a ed. São Paulo: Hucitec; 2012.

15. Brasil. Ministério da Justiça. Departamento Penitenciário Nacional. Diretoria do Sistema Penitenciário Federal. Portaria n. 63, de 8 de abril de 2009. Aprova o Manual de Assistências do Sistema Penitenciário Federal, aplicável no âmbito das Penitenciárias Federais, na forma dos Anexos a esta Portaria [Internet]. Brasília; 2009 [cited 2016 Dez 27]. Available from: http://www.justica. gov.br/seus-direitos/politica-penal/arquivos/ sistema-penitenciario-federal/anexos-sistemapenitenciario-federal/2009portariadepen63.pdf

16. Locatelli PAPC, Brunetta N, Oliveira LYM, Piccinini VC. Mulheres na polícia civil: um olhar sobre as relações de gênero e identidade. Gestão Contemporânea [internet]. 2013 [cited 2016 Aug 27];10(14):9-34. Available from: http://seer4.fapa. com.br/index.php/arquivo/article/view/178

17. Siqueira ACA. Masculinidades, trabalho e cuidado em saúde: representações de trabalhadores no contexto de modernização do porto de Santos-SP [tese]. São Paulo (SP): Universidade de São Paulo; 2014.

18. Tschiedel RM, Monteiro JK. Prazer e sofrimento no trabalho das agentes de segurança penitenciária. Estud psicol. [internet]. 2013 [cited 2016 Aug 10];18(3):527-35. Available from: http://www.scielo.br/scielo.php?script $=$ sci_ arttext\&pid=S1413-294X2013000300013

19. Alves V, Binder MCP. Trabalhar em penitenciárias: violência referida pelos trabalhadores e (in) satisfação no trabalho. Rev bras saúde ocup [internet]. 2014 [cited 2016 Sept 12];39(129):5062. Available from: http://www.scielo.br/scielo. php?pid $=$ S0303- $76572014000100050 \&$ script $=$ sci abstract\&tlng=pt

20. Jaskowiak CR, Fontana RT. O trabalho no cárcere: reflexões acerca da saúde do agente penitenciário. Rev bras Enferm [internet]. 2015 [cited 2016 Aug 20];68(2):235-43. Available from: http://www.scielo.br/scielo.php?script=sci_ arttext\&pid=S0034-71672015000200235

21. Goffman E. Manicômios, prisões e conventos. Tradução de Dante Moreira Leite. 7a ed. São Paulo: Perspectiva; 2001.

22. Brasil. Ministério da Saúde. Plano Nacional de saúde no Sistema Penitenciário [internet]. Brasília; 2004 [cited 2017 July 19]. Available from: http:// bvsms.saude.gov.br/bvs/publicacoes/cartilha_ pnssp.pdf

23. Apolinário FH. Significados atribuídos por enfermeiros a assistência que prestam a indivíduos em situação prisional [dissertação]. Botucatu (SP): Universidade Estadual Paulista; 2013.

24. Constantino P, Assis SG, Pinto LW. O impacto da prisão na saúde mental dos presos do estado do Rio de Janeiro, Brasil. Ciênc saúde coletiva [internet]. 2016 [cited 2016 Sept 29];21(7):2089-100. Available from: http://www.scielo.br/scielo.php?pid=\$1413$81232016000702089 \&$ script=sci_abstract\&tlng=pt

25. Miranda TMM, Petriccione S, Ferracini FT, Borges Filho WM. Intervenções realizadas pelo farmacêutico clínico na unidade de primeiro atendimento. Einstein [internet]. 2012 [cited 2016 Oct 29];10(1):74-8. Available from: http://www.scielo.br/scielo.php?script=sci_ a r t ext \& n r m = i s o \& $1 \mathrm{ng}=$ p t \& t 1 n g = pt\&pid=S1679-45082012000100015

26. Brasil. Lei n. 11.907, de 2 de fevereiro de 2009. Estrutura a Carreira de Agente Penitenciário Federal, de que trata a Lei n. 10.693, de 25 de junho de 2003; cria as Carreiras de Especialista em Assistência Penitenciária e de Técnico de Apoio à Assistência Penitenciária entre outros. [Internet]. Brasília; 2009 [cited 2014 Mar 10]. Available from: http://www.planalto.gov.br/ccivil_03/_ato20072010/2009/lei/111907.htm

27. Biasi EY. Processos identitários do agente de escolta e vigilância penitenciária: recorte discursivo do trabalho nas muralhas [dissertação]. 
Três Lagoas (MS): Universidade Federal do Mato Grosso do Sul; 2016.

28. Greco PBT, Magnago TSBS, Beck CLC, Urbanetto JS, Prochnow A. Estresse no trabalho em agentes dos centros de atendimento socioeducativo do Rio Grande do Sul. Rev gaúcha enferm [internet]. 2013 [cited 2016 Oct 29];34(1):94-103. Available from: http://www.scielo.br/scielo.php?script=sci_ arttext\&pid=S1983-14472013000100012

29. Almeida CA, Cruz SS. Sistema penitenciário brasileiro: uma análise da penitenciária industrial regional do Cariri-PIRC. Rev Direito \& Dialogicidade [internet]. 2014 [cited 2016 Oct
29];5(2):75-89. Available from: http://periodicos. urca.br/ojs/index.php/DirDialog/article/view/878

30. Machado MH, Santos MR, Oliveira E, Wermelinger M, Vieira M, Lemos W, et al. Condições de trabalho da enfermagem. Enferm. foco [internet]. 2016 [cited 2017 Mar 8];7(Esp):63-76. Available from: http://revista.portalcofen.gov.br/index.php/ enfermagem/article/view/695/305

Recebido: 28 de março de 2017

Aprovado: 23 de agosto de 2017

Publicado: 30 de outubro de 2017 